This work was carried out in Paris during the tenure of an exchange scholarship of the Medical Research Council and the Centre National de la Recherche Scientifique.

Service de Chimie Microbienne,

$$
\text { STEPHEN V. BOYDEN }
$$

Institut Pasteur,

Paris.

Sept. 29.

${ }^{1}$ Keogh, E. V., North, E. A., and Warburton, M. F., Nature, 161, $687(1948)$.

${ }^{2}$ Middlebrook, G., and Dubos, R. J., J. Exp. Med., 88, 521 (1948).

${ }^{3}$ Boyden, S. V., and Suter, W. E., J. Immunol., 68, 577 (1952).

${ }^{4}$ Lamensans, A., Grabar, P., and Bretey, J., C.R. Acad. Sci., Paris, 230, 1967 (1951).

\section{Cost of German Medical and Scientific Periodicals}

Dr. W. Bonser and Miss Margaret P. Russell have discussed the prices of German medical and scientific periodicals in Nature of September 13, 1952 p. 446.

The prices of the periodicals published by the Springer Verlag are fixed in such a way that the number of subscriptions wholly, or at least approximately, covers the costs of production. It is only through subsequent orders that a profit is made. This method automatically leads to a reduction in price when the number of subscribers jncreases. Thus in July 1952, we announced reduced prices for 1953 for the following periodicals : Zeitschrift für Physik, Zeitschrift für analytische Chemie, Biochemische Zeitschrift (by DM 10 per volume), and Archiv für experimentelle Pathologie und Pharmakologie (by DM 8 per volume), that is, some DM 30 less per annum for each of the four periodicals.

A comparison with the cost of periodicals from other countries, particularly from Anglo-Saxon countries, is misleading, for conditions there are quite different.

(1) The number of subscribers is much larger than that to German periodicals. For example, the number of subscribers to the Zeitschrift für Krebsforschung is 400, and to Cancer 4,000. Our experience is that a reduction in price would not essentially change this proportion. We publish many special periodicals demanding numerous illustrations of high standard, and appealing to only a few hundred subscribers.

(2) Especially in the United States and Great Britain, the periodicals often receive financial support either from scientific socicties or universitics, or from the Government or from the author himself. For example, in the Physical Review and Journal of Chemical Physics, the author or his institute has to contribute 15 dollars per page. For the Journal of Neuropathology the author is not reimbursed for his expenses nor does he receive free separate prints, but is asked to answer for part of the costs of production.

With reference to particular points made by Dr. Bonser and Miss Russell, we wish to make the following comments :

(1) Annual cost. Since 1933, foreign libraries have received price lists every year showing the maximum cost for the coming year.

(2) With the exception of one Swiss journal erroneously mentioned, the list supplied to us by Dr. Bonser and Miss Russell in which Springer periodicals are compared with periodicals of other German publishing houses contains only periodicals which are published-or at least printed-in the
Eastern Zone of Germany, where the costs of production are at most one-half as high, not considering the difference in currency exchange.

(3) The tables of the detailed list which Dr. Bonser and Miss Russell were kind enough to let us have can scarcely be considered as a basis, in so far as (a) a comparison is made not of the prices per sheet but of the total prices without regard to number of pages and get-up (number and quality of illustrations) ; (b) devaluation of sterling is mentioned but not allowed for in the tables; (c) it was due to measures (now abandoned) taken by the German Government to promote export that, during 1935-45, selling prices abroad wore 25 per cent lower than on the home market.

Springer periodicals are published at the expense and risk of the publishing house alone. Costs of production of West Germain publishing houses had risen in 1949 to two and a half times the pre-war level and are now three times as high. The prices per sheet of Springer periodicals, on the other hand, average only twice as high as before the War.

Neuenheimer Landstrasse 24, SPR!NGer VERLAG Heidelberg.

WE wish to make the following reply to some of the points in the above letter from the Springer Verlag. It quotes from the fuller version of our paper, necessarily condensed in Nature, but now widely circulated.

The primary fact that the cost of German, and especially of Springer's, periodicals is far in excess of that of other countries still holds. The reduction in their salos which is likely to result must prove detrimental, scientifically as well as financially, to German progress.

The Springer Verlag points out that its periodicals are completely its own financial venture. We have already suggested, in our fuller paper, that a solution to the problem might be a change-over of responsibility to the German societies concerned, as has been done for certain publications in Great Britain and the United States.

We should like to reply to the following comments on details.

(2) Tho Swiss journal (Annales Podiatrici) was not "erroneously mentioned" but was intentionally included, since it is the continuation of the German journal Jahrbuch für Kinderheilkunde, both of which have the same publisher now in Basle but formerly (until the end of 1938) in Berlin.

(3a) We actually did compare two journals from the point of view mentioned, namely, the British Journal of Experimental Pathology and the Archiv für experimentelle Pathologie, to the great disadvantage of the Spring $>\mathbf{r}$ periodical ; $(3 b)$ it was pointed out that devaluation of sterling amounted to 45 per cent for American and only 26 per cent for German periodicals- the figures presented in our table are the resultant prices paid by us.

We feel that our table of comparisons still stands as a summary of facts, and we still hope that some means of reducing the cost of these essential contributions to knowledge, so as to be comparable with those of other German firms, may be possible. WILFRID BONSER Margaret P. Russell

Medical School,

University of Birmingham. 